\title{
Radiological appearances of hydatid disease in Wales
}

\author{
Richard Clements and I. Huw Gravelle
}

Department of Radiology, University Hospital of Wales, Heath Park, Cardiff CF4 4XN,UK.

\begin{abstract}
Summary: Thirty six patients with hydatid disease have been investigated in the Radiology Departments of Cardiff hospitals between June 1973 and June 1984; thirty two of these patients are likely to have acquired the disease in Wales. There were 16 hepatic cysts, 3 renal cysts, 2 cerebral cysts, 15 pulmonary cysts, 1 pleural cyst, 1 recurrent spinal cyst, and 1 cyst of the broad ligament. The radiological features are discussed. These patients emphasize the higher incidence of hydatid disease in Wales, compared with other regions of the United Kingdom, and the need to consider this diagnosis in Welsh patients from rural areas, who have large pulmonary opacities, or hepatic, renal, or cerebral cystic abnormalities.
\end{abstract}

\section{Introduction}

Hydatid cysts are caused by tissue infection by the larval stage of Taenia echinococcus, a parasitic tapeworm. Human hydatid disease is endemic in many sheep and cattle rearing countries such as Australia, the Middle East, Greece and Yugoslavia (Schwabe, 1968), but is generally considered to be a rare disease in the United Kingdom. Wales has a relatively high incidence of hydatid disease (Howell, 1938; Jonathan, 1960; Waters, 1977; Morris, 1981) and the radiological features of proven cases of hydatid disease presenting to the Cardiff hospitals over an eleven year period have been reviewed.

\section{Materials and methods}

Between June 1973 and June 1984, 36 patients with histologically proven hydatid diseases have been investigated in the radiology departments of the University Hospital of Wales, Cardiff Royal Infirmary and Llandough Hospital. Patients were traced via departmental records, and a hospital inpatient computer search. The location of the cysts in the 36 patients is shown in Tables I and II.

Four of these patients may have acquired the disease in endemic areas overseas, but in 32 of the 36 patients the disease was apparently acquired in Wales. The majority of these patients came from rural sheep rearing areas in South and Mid-Wales and a large number were farmers, farmers' relatives or farm labourers.

Correspondence: R. Clements, M.A., B.M., B.C., F.R.C.S., F.R.C.R.

Accepted: 1 August 1985
All cases in this series have been histologically proven. Many other patients have been examined during this period who have calcified circular opacities in the liver region on their plain abdominal radiographs. These are probably calcified hepatic cysts, but such patients have not been included in the series unless the diagnosis has been confirmed at operation.

\section{Radiological appearances}

\section{Pulmonary hydatid cysts}

The radiological appearances of a simple pulmonary hydatid cyst are those of a round or oval, well-defined opacity of variable size (Figures 1 and 2). In cases of cyst rupture, fluid may spread into the tissues around the cyst, and give the radiological appearances of an ill-defined area of pneumonic consolidation. As the cyst grows, it may erode a bronchiole and produce characteristic radiological appearances because of air between the pericyst and endocyst. This may vary from a thin crescent of air to the 'water lily' sign (Figure 3). The latter sign was present in 3 of our patients and is produced when the collapsed endocyst membrane floats on top of the remaining fluid.

Previous studies of the radiological features of pulmonary hydatid disease have been reported. (McPhail \& Arora 1967; Balikian \& Mudarris, 1974). Cysts were found most commonly in the right lower lobe (35\% of patients); $15 \%$ of cysts were found in the right middle lobe, $10 \%$ in the right upper lobe, $22 \%$ of cysts were in the left lobe and $18 \%$ in the left upper lobe. It is important to emphasize the occurrence of 
Table I Location of hydatid cysts in 36 patients

\begin{tabular}{|c|c|c|c|c|c|}
\hline Cyst site & Number of patients & Average age & Clinical presentati & & Special features \\
\hline Chest & 16 & 34 & $\begin{array}{l}\text { Dyspnoea } \\
\text { Haemoptysis } \\
\text { Cough } \\
\text { Asymptomatic } \\
\text { No details }\end{array}$ & $\begin{array}{l}3 \\
3 \\
2 \\
5 \\
3\end{array}$ & $\begin{array}{l}11 \text { solitary cysts } \\
4 \text { multiple cysts } \\
1 \text { pleural cyst }\end{array}$ \\
\hline Liver & 13 & 54 & $\begin{array}{l}\text { Hepatomegaly } \\
\text { Abdominal pain } \\
\text { No details }\end{array}$ & $\begin{array}{l}2 \\
9 \\
4\end{array}$ & $\begin{array}{l}9 \text { in right lobe } \\
5 \text { in left lobe } \\
3 \text { patients had daughter } \\
\text { cysts in the common bile } \\
\text { duct }\end{array}$ \\
\hline Brain & 1 & 10 & $\begin{array}{l}\text { Headache and } \\
\text { right sided } \\
\text { weakness }\end{array}$ & & Left parietal cyst \\
\hline $\begin{array}{l}\text { Brain and } \\
\text { liver }\end{array}$ & 1 & 10 & $\begin{array}{l}\text { Right sided } \\
\text { weakness }\end{array}$ & & Left parietal cyst \\
\hline Kidney & 2 & 37 & Loin mass & & $\begin{array}{l}\text { One patient had multiple } \\
\text { renal cysts }\end{array}$ \\
\hline $\begin{array}{l}\text { Kidney and } \\
\text { liver }\end{array}$ & 1 & 21 & $\begin{array}{l}\text { Anaphylactic } \\
\text { shock }\end{array}$ & & $\begin{array}{l}\text { Ruptured cyst in right } \\
\text { lobe of liver } \\
\text { Also cyst in right kidney }\end{array}$ \\
\hline Spine & 1 & 51 & Left leg weakness & & $\begin{array}{l}\text { Previous spinal cysts } \\
\text { Previous hepatic cysts }\end{array}$ \\
\hline $\begin{array}{l}\text { Pelvis and } \\
\text { liver }\end{array}$ & 1 & 23 & Infertility & & $\begin{array}{l}\text { Cysts in right broad } \\
\text { ligament, and in right } \\
\text { lobe of liver }\end{array}$ \\
\hline
\end{tabular}

Table II Location of thoracic cysts in 16 patients

\begin{tabular}{lll}
\hline Type of cyst & $\begin{array}{l}\text { Number of } \\
\text { patients }\end{array}$ & Site of cyst \\
\hline $\begin{array}{l}\text { Single } \\
\text { pulmonary } \\
\text { cyst }\end{array}$ & 11 & $\begin{array}{l}\text { LLL 5 } \\
\text { RLL 4 } \\
\text { RUL 2 }\end{array}$ \\
$\begin{array}{l}\text { Multiple } \\
\text { pulmonary } \\
\text { cysts }\end{array}$ & 4 & $\begin{array}{l}\text { LLL + RLL 1 } \\
\text { LUL + RLL 2 }\end{array}$ \\
$\begin{array}{l}\text { Pleural } \\
\text { cyst }\end{array}$ & 1 & $\begin{array}{l}\text { In region of } \\
\text { left 4th rib }\end{array}$ \\
\hline
\end{tabular}

LLL: left lower lobe; RLL: right lower lobe; LUL: left upper lobe; RUL: right upper lobe.

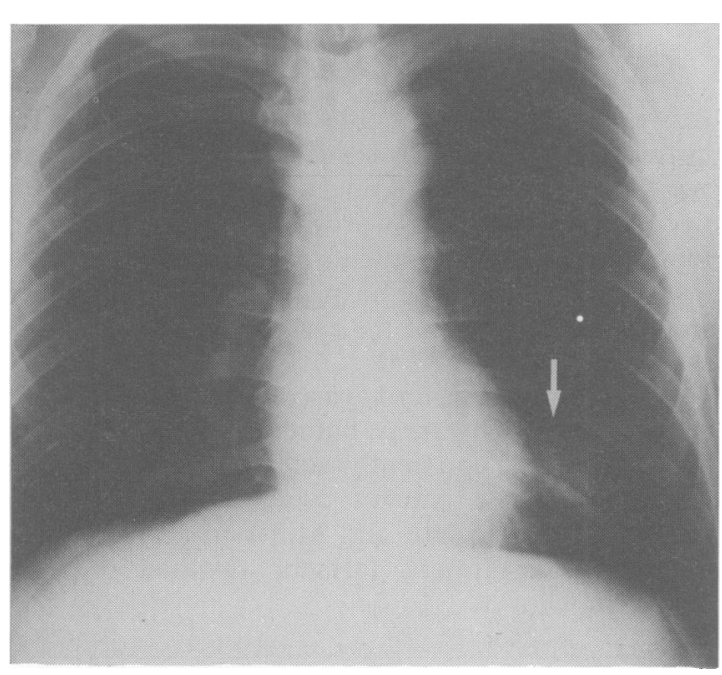

Figure 1 PA chest radiograph: left lower lobe hydatid cyst adjacent to left heart border. 


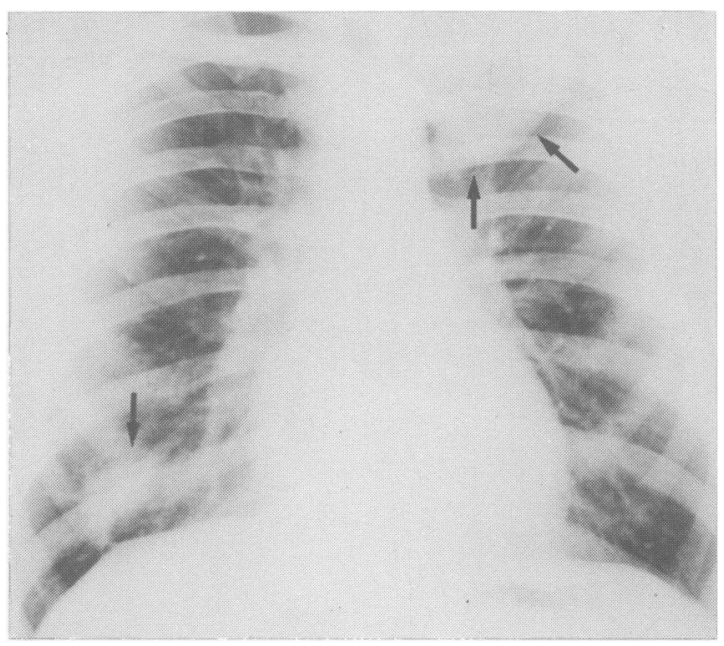

Figure 2 PA chest radiograph: large apical left upper lobe hydatid cyst and small right lower lobe hydatid cyst (arrows).

upper lobe cysts, as this fact is often not appreciated, when considering the differential diagnosis of rounded opacities seen in the upper lobes of a chest radiograph. Multiple pulmonary cysts have been reported in $30-40 \%$ of patients in different series. Bilateral cysts were present in $20 \%$ of patients in the series reported by Balikian \& Mudarris (1974). Pleural cysts are reported in $2-5 \%$ of cases in previous series.

Radiological calcification in thoracic hydatid cysts is extremely rare and was not present in any of our cases, or in the series of Balikian \& Mudarris (1974).

\section{Hepatic cysts}

Eighty per cent of hepatic hydatid cysts are reported to occur in the right lobe of the liver (Little, 1976), and the radiological features of hepatic hydatid cysts have been recently reviewed (Beggs, 1983).

Hepatic cysts may be identified by calcification on abdominal radiographs. The calcification varies from a thin curvilinear rim to a diffuse dense circular pattern (Figure 4); calcification was present in 7 of our 16 cases $(43 \%)$.

Various imaging techniques may be used to detect hepatic hydatid cysts and isotope liver scans, ultrasonography, and computerized tomography (CT) have been used in Cardiff during the last 10 years. Isotope liver scans (Figure 5) were used initially and revealed areas of diminished radioisotope uptake at the site of the hepatic hydatid cyst. In recent years, ultrasonography and CT have been used in preference to isotope liver scanning in Cardiff. CT has generally been found

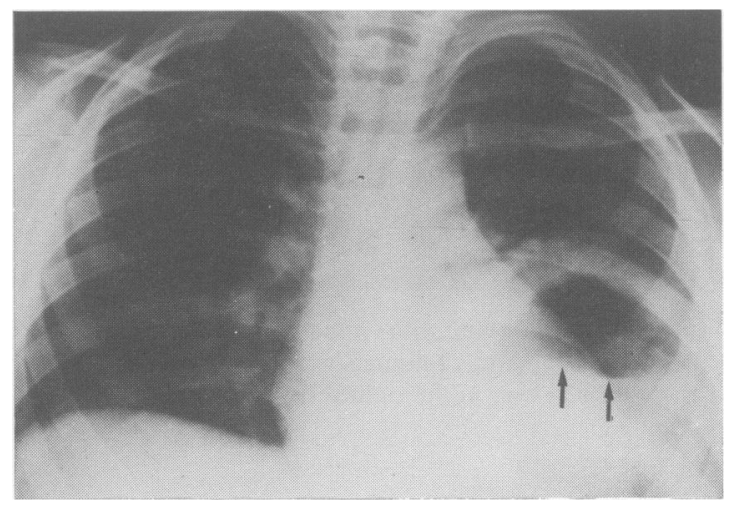

Figure 3 PA chest radiograph: left lower lobe hydatid cyst. Note 'water lily' sign produced by collapsed cyst membrane (arrows).

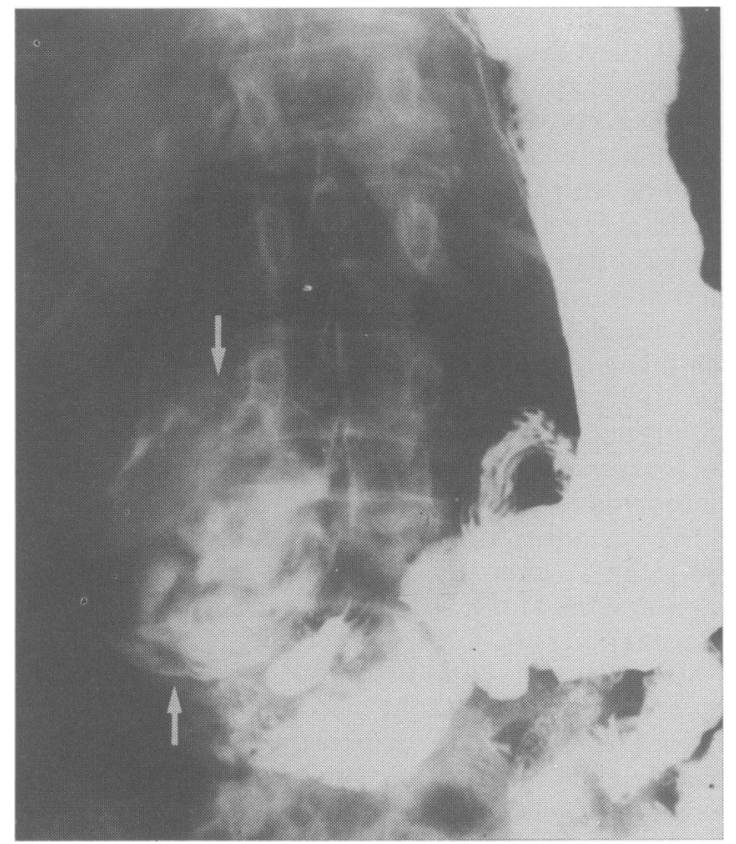

Figure 4 Barium meal examination: note calcified hydatid cyst in right lobe of liver. 


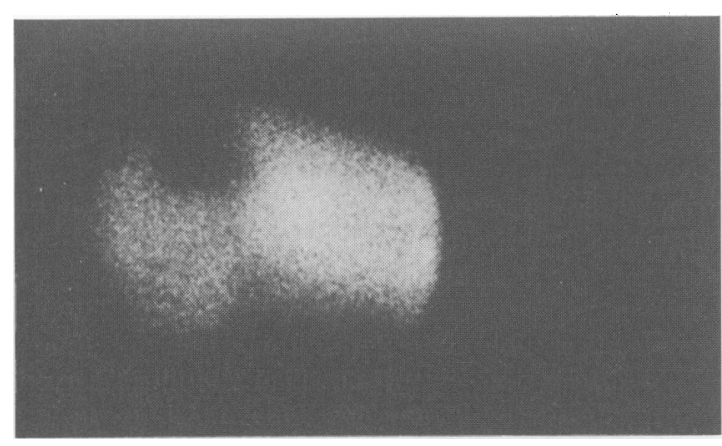

Figure 5 Right anterior oblique isotope liver scans demonstrating area of diminished isotope uptake caused by a hydatid cyst in the right lobe of the liver.

more useful than ultrasound in the assessment of hepatic hydatid disease, as it can more accurately define the number and extent of the cysts.

The ultrasonic features of hepatic hydatid cysts were reviewed by Beggs (1983). Most hepatic hydatid cysts appeared as well-defined thin walled anechoic areas with distal enhancement. In some cysts, a fluid level caused by debris within the cyst was described, and in other patients, separation of the laminated membrane from the pericyst gave the ultrasonic appearance of a 'floating membrane', as seen in Figure 6.

Ismail et al. (1980) reported the CT appearances of 121 hepatic hydatid cysts. The characteristic appearance they described was of a well-defined area of decreased attenuation. Calcification may be identified which is not visible on abdominal radiography, and a multilocular appearance due to daughter cysts may also be seen (Figure 7).

Surgery remains the primary treatment for hepatic hydatid disease. Both mebendazole and albendazole have been claimed to be effective in the treatment of hydatid disease, and have been reported to cause cyst shrinkage on serial ultrasonography and CT (Bekhti $e t$ al., 1977; Morris et al., 1983). These drugs are given orally but are very poorly soluble and we are not aware of any reports in the literature of their direct injection into hydatid cysts.

The majority of hepatic hydatid cysts are treated surgically, and the post-operative radiological appearances of the cyst cavity have been described by Beggs et al. (1983): If the cyst cavity has been packed with omentum, it appears ultrasonographically as an hypoechoic area without distal enhancement. CT in these circumstances demonstrates an area with negative CT attenuation values, because of the fat content of omentum.

A growing cyst may communicate with the biliary tree due to local pressure atrophy, and daughter cysts may be found in the common bile duct in these

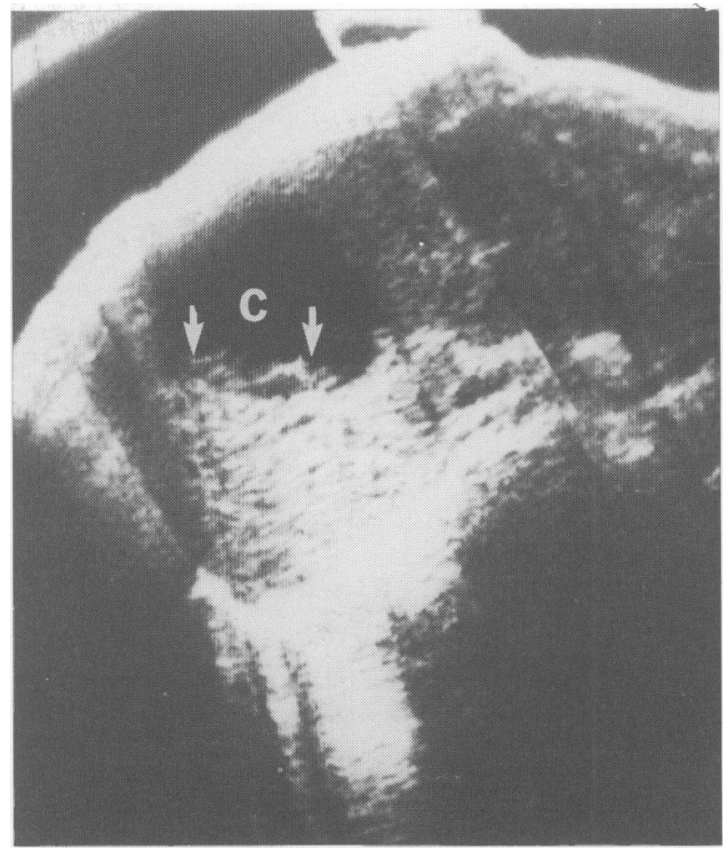

Figure 6 Oblique ultrasonic scan through liver: hydatid cyst $(C)$ in right lobe of liver with ultrasonic 'water lily' sign (arrows) caused by collapsed cyst membrane.

circumstances. Common bile duct cysts were seen in 3 of our patients (Figure 8). A communication between the biliary system and a hepatic hydatid cyst was reported in $16 \%$ of liver hydatids (Kattan, 1977); operative cholangiography and post-operative T-tube cholangiography may be useful in these circumstances to outline daughter cysts.

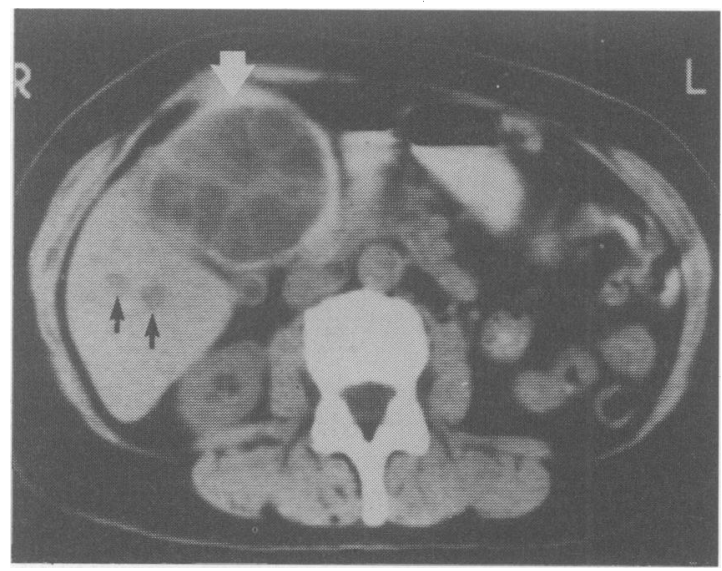

Figure 7 CT scan through liver: large multiocular cyst (broad arrow) in right lobe with 2 small cysts adjacent (narrow arrows). 


\section{Renal hydatid cysts}

Urological aspects of hydatid disease were reviewed by Kirkland (1968), who reported renal cysts in $2 \%$ of patients with hydatid disease. Renal hydatid cysts are usually single and it is rare to find multiple hydatid cysts in a kidney (Figure 9).

Abdominal radiography may show a soft tissue mass in the loin if the kidney is enlarged by a hydatid cyst. Calcification within the wall of a renal hydatid cyst may be observed, but this is not a helpful feature in differential diagnosis as calcification may also be seen in a small percentage of both simple renal cysts and hypernephromas.

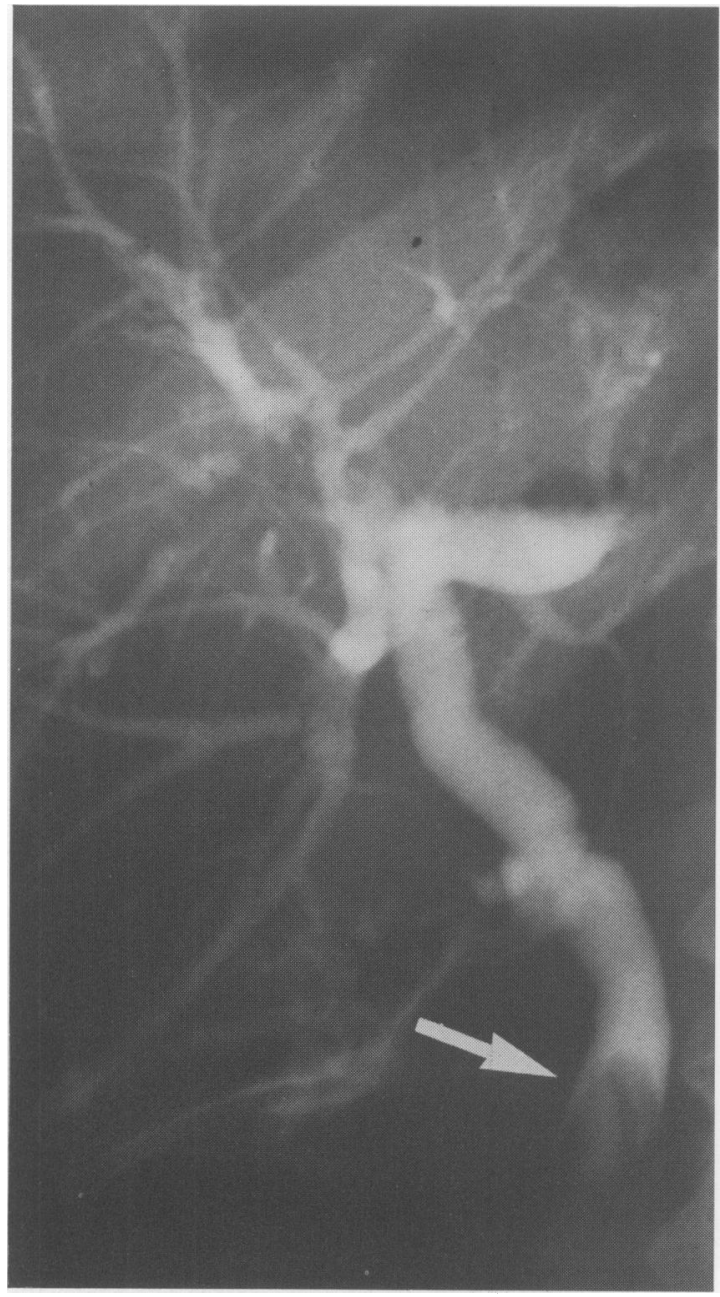

Figure 8 Post-operative cholangiogram: filling defect (arrow) due to daughter cyst in lower end of common bile duct.
The pyelographic appearance of renal hydatid cysts is variable, depending whether the cyst communicates with the renal pelvis. If the cyst wall is intact, intravenous pyelography will reveal a smooth spaceoccupying lesion within the kidneys displacing the normal calyceal outline (Figure 9); if the cyst communicates with the pelvis, then the cyst may be outlined by contrast and the communication with the renal pelvis demonstrated.

Ultrasonography and CT may be used in the further radiological assessment of renal hydatid cysts, and an
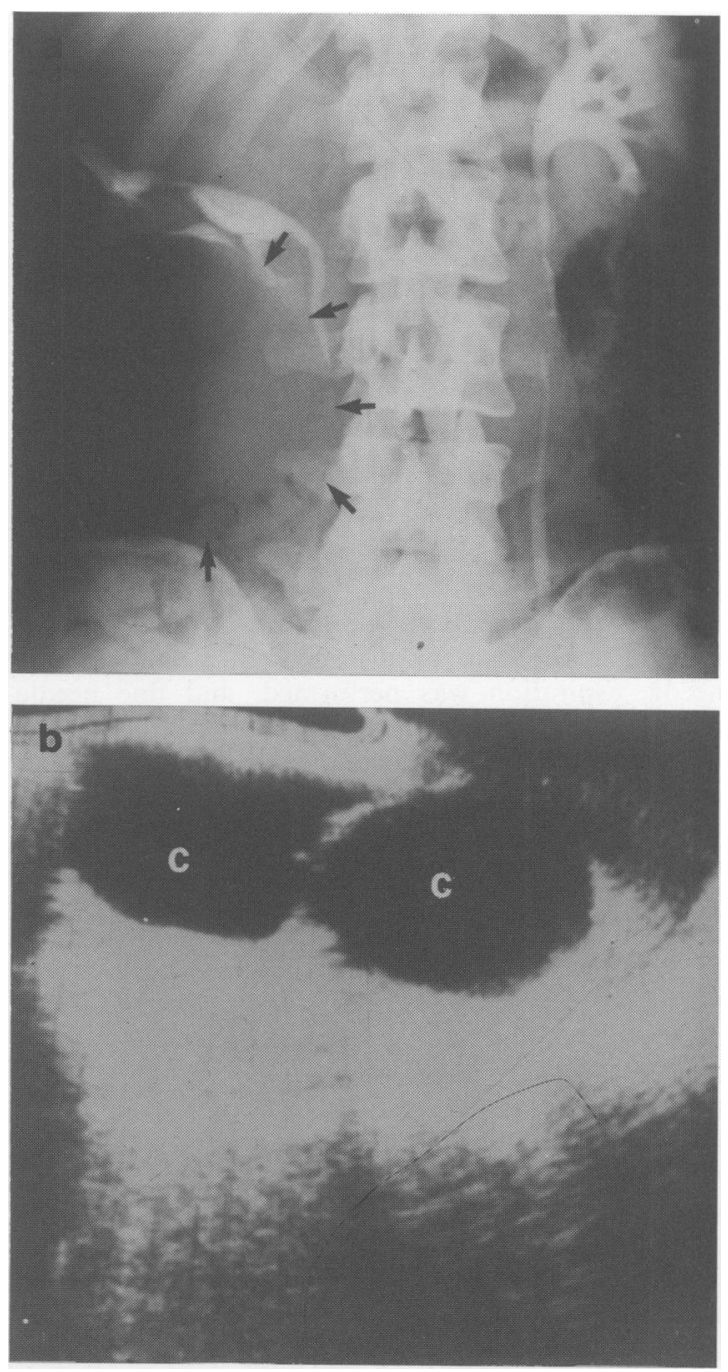

Figure 9 (a) Intravenous pyelogram (15 minute film): Note calyceal displacement by 2 large cysts in upper and lower poles of right kidney; lower pole cyst outlined (arrows). (b) Longitudinal ultrasonic scan of right kidney of same patient showing both cysts (C). 
ultrasonic scan of a hydatid cyst of the upper pole of the left kidney is illustrated in Figure 10.

\section{Cerebral hydatid cysts}

About $3 \%$ of cases of hydatid disease develop cerebral cysts, and most of these are in the parietal lobe. The cysts grow slowly and can reach an enormous size. Cyst calcification may been on plain skull radiography or CT (Figure 11).

\section{Bone hydatid cysts}

These are rare, and occur in about $2 \%$ of patients with hydatid disease. Most cases are in the vertebrae or pelvis, but femora, tibiae, humeri and the skull may be involved. Enlarging hydatid cysts cause pressure atrophy of bony trabeculae, and the patient may present with a pathological fracture. There is a wide differential diagnosis of the radiological appearance, but the diagnosis of hydatid cyst should be considered in a patient from an endemic area.

\section{Discussion}

The present series of patients is a reminder that hydatid disease occurs in South Wales and that residence in an endemic area overseas is not a prerequisite for developing the condition.

In several patients in the series, the diagnosis of hydatid disease was unsuspected. In 2 patients, fine needle aspiration was performed, and fine needle percutaneous transhepatic cholangiography (PTC) was performed in 2 other patients. None of these 4 patients developed an anaphylactic reaction or has subsequently developed recurrent hydatid disease at the site of the original cyst.

It is said that fine needle aspiration and PTC is contraindicated in patients with hydatid disease because of the risk of anaphylaxis. We have been unable to find any reports of the risks of anaphylaxis with fine needle techniques. Inadvertent fine needle puncture of an unsuspected renal hydatid cyst has been previously described (Roylance et al., 1973), and Tuttle (1970) performed percutaneous cholangiography with a large bore needle. It may be that the risks of anaphylaxis with fine needle aspiration are lower than generally accepted. Radiographic contrast media was injected via the fine needle in 3 of the 4 patients in Cardiff. The use of contrast media may possibly have contributed to the absence of anaphylaxis and other side effects in these 3 patients.

One patient had multiple daughter cysts demonstrated in the common bile duct by PTC and yet at laparotomy a few days later, no daughter cysts in the common bile duct were found. It is possible that the

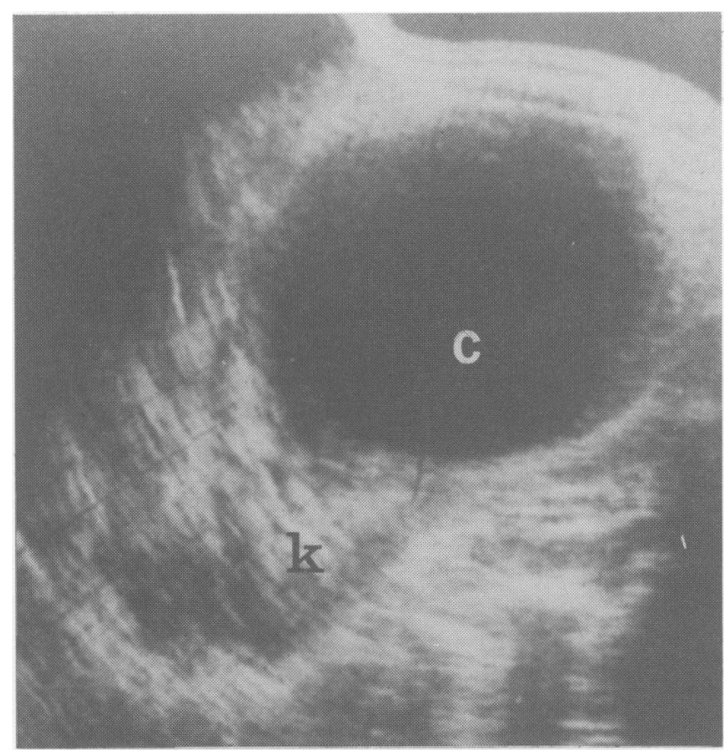

Figure 10 Longitudinal ultrasonic scan of kidney showing large renal hydatid cyst (C) and normal kidney tissue (k).

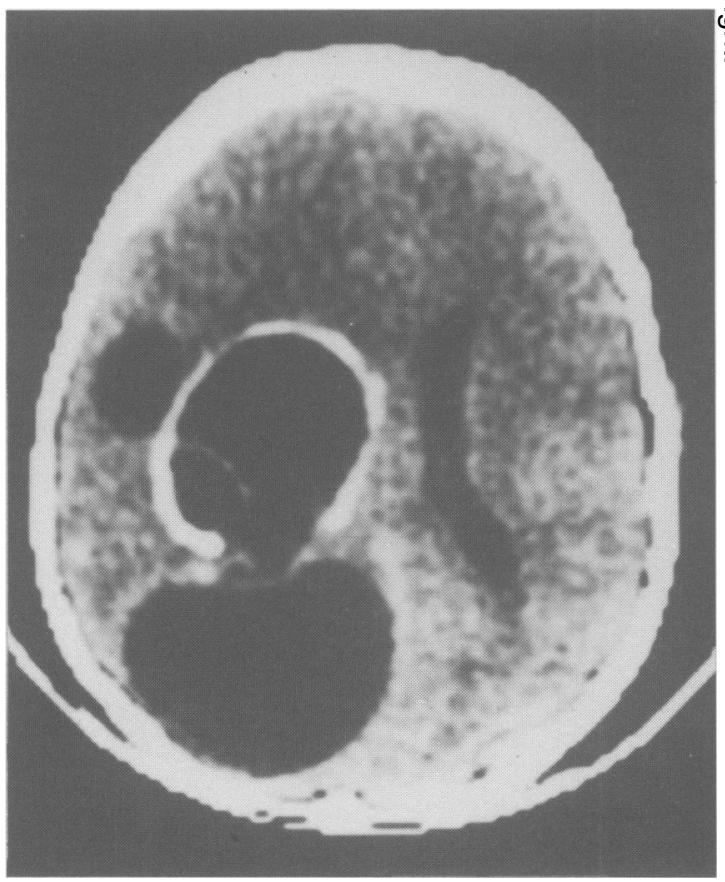

Figure 11 Cranial CT scan of a partially calcified multiloculated cyst in the left parietal lobe. 
high osmolarity of the contrast media caused shrinkage of the cysts; however, no reports of any toxic effects of radiographic contrast media on hydatid cysts, or the possible therapeutic use of contrast media during diagnostic aspiration have been found in the literature.

\section{References}

BALIKIAN, J.P. \& MUDARRIS, F.F. (1974). Hydatid disease of the lungs: a roentgenologic study of 50 cases. American Journal of Roentgenology, 122, 692.

BEGGS, I. (1983). The radiological appearances of hydatid disease of the liver. Clinical Radiology, 34, 555.

BEGGS, I., WALMSLEY, K. \& COWIE, A.G.A. (1983). The radiological appearances of the liver after surgical removal of hydatid cyst. Clinical Radiology, 34, 565.

BEKHTI, A., SCHAPPS, J.P., CAPRON, M., DESSAINT, J.P., SANTORO, F. \& CAPRON, A. (1977). Treatment of hydatid disease with mebendazole: preliminary results in 4 cases. British Medical Journal, 2, 1047.

HOWELL, N. (1938). On the State of the Public Health: Annual Report of the Chief Medical Officer of the Ministry of Health. p. 192. H.M.S.O.

ISMAIL, M.A., AL-DABAGH, M.A., AL-JANABI, T.A., ALMOSLIH , M.I., AL-ANI, M.S., RASSAM, S., FAWZI, A.H., SHAFIK, M.A. \& AL-RAWAS, A.Y. (1980). The use of computerised axial tomography (C.A.T.) in the diagnosis of hydatid cysts. Clinical Radiology, 31, 287.

JONATHAN, O.M. (1960). Hydatid disease in North Wales. British Medical Journal, 1, 1246.

KATTAN, Y.B. (1977). Intrabiliary rupture of hydatid cysts of the liver. Annals of the Royal College of Surgeons of England, 59, 108.

\section{Acknowledgements}

We wish to thank the clinicians concerned for allowing us to report their cases, and our radiological colleagues in the University Hospital of Wales, and Dr Margaret Jones and her colleagues in the Radiology Department, Llandough Hospital for providing radiographs. We finally wish to thank Mrs J. Heyburn for typing the manuscript and for expert secretarial assistance.

KIRKLAND, K. (1966). Urological aspects of hydatid disease. British Journal of Urology, 38, 241.

LITTLE, J.M. (1976). Hydatid disease at Prince Alfred Hospital 1964-74. Medical Journal of Australia, 1, 903.

MCPHAIL, J.L. \& ARORA, T.S. (1967). Intrathoracic hydatid disease. Diseases of the Chest, 52, 772.

MORRIS, D.L. (1981). Management of hydatid disease. British Journal of Hospital Medicine, 25, 586.

MORRIS, D.L., DYKES, P.W., DICKSON, B., MARRINER, S.E., BOGAN, J.A. \& BURROWS, F.G.O. (1983). Albendazole in hydatid disease. British Medical Journal, 286, 103.

PAPADIMITROU, J. \& MANDREKAS, A. (1970). The surgical treatment of hydatid disease of the liver. British Journal of Surgery, 57, 431.

ROYLANCE, J., RHYS DAVIES, E. \& ALEXANDER, W.D. (1973). Translumbar puncture of a renal hydatid cyst. British Journal of Radiology, 46, 960.

SCHWABE, C.W. 1968). Epidemiology of echinoccosis. Bulletin of the World Health Organisation, 39, 131.

TUTTLE, R.J. (1970). Cause of recurring obstructive jaundice revealed by percutaneous cholangiography - hydatid cyst. New England Journal of Medicine, 283, 805.

WALTERS, T.M.H. (1977). Hydatid disease in Wales. Transactions of the Royal Society of Tropical Medicine and Hygiene, 71, 105. 